\title{
A chemical patterning approach of dense and porous titanium surfaces by using a combination of concentrated acid and oxidant
}

\author{
Alexandre Antunes Ribeiro ${ }^{1}$, Rodrigo Sacramento da Silva ${ }^{1}$, \\ Débora Vieira Way ${ }^{1}$, Lais de Souza Alves ${ }^{1}$, Erika Batista Silveira ${ }^{2}$, \\ Fabiana Magalhães Teixeira Mendes ${ }^{2}$, Marize Varella de Oliveira ${ }^{1}$
}

\footnotetext{
${ }^{1}$ Powder Technology Laboratory, Division of Materials, National Institute of Technology, No. 82 Venezuela Avenue, Room 602, CEP: 20081-312, Rio de Janeiro, RJ, Brazil.

${ }^{2}$ Laboratory of Combinatorial Catalysis, Catalysis and Chemical Processes Division, National Institute of Technology, No. 82 Venezuela Avenue, Room 110, CEP: 20081-312, Rio de Janeiro, RJ, Brazil.

e-mail: alexandre.antunes@int.gov.br, rodrigosacra@gmail.com,debora.vieira@int.gov.br, lais.souza@int.gov.br, varella_marize@yahoo.com.br, erika.silveira@int.gov.br, fabiana.mendes@int.gov.br
}

\begin{abstract}
Commercially dense pure titanium sheets and porous titanium samples processed by powder metallurgy were treated with a mixture consisting of equal volumes of $\mathrm{H}_{2} \mathrm{SO}_{4}$ and $\mathrm{H}_{2} \mathrm{O}_{2}$ for 2 or 4 hours. Characterization was performed by scanning electron microscopy, energy dispersive X-ray spectroscopy, confocal scanning optical microscopy, X-ray diffraction, and X-ray photoelectron spectroscopy. The analyses showed that the chemical patterning approach using a combination of concentrated acid and oxidant was able to generate a nanotexture on dense and porous titanium surfaces. In addition, the treated samples presented an oxide layer consisting predominantly of titanium dioxide with negative charge conferred by the presence of hydroxyl groups, which is an important factor that favors apatite nucleation and protein adsorption. It was also observed that oxide formation was more effective on porous samples than on dense samples, which can be explained by the higher surface area intrinsic to porous media. Finally, the findings indicated that both treatment times promoted similar modifications in surface properties, such as nanotexture and chemical composition, suggesting that the time of 2 hours were enough to induce the surface alterations at the nanoscale.
\end{abstract}

Keywords: titanium; surface modification; chemical oxidation, powder metallurgy.

\section{INTRODUCTION}

Surface properties can affect the tissue/implant interaction, including composition, surface energy, roughness and topography. With proper control and management, manipulation of surface features may hold the key to developing innovative materials that not are easily accepted by the human body but can have a subsequent functional effect [1-4].

Researchers have demonstrated that titanium (Ti) and titanium alloy implants with porous structures can encourage osteointegration and prevent implantation failure by providing space for bone cells, vascular and bone tissue ingrowth in order to achieve mechanical interlocking [5, 6]. Further, advances in nanotechnology may provide biocompatibility improvements by surface modification at the nanoscale, since that nanostructure can also influence the behavior of various cell types [7, 8].

Powder metallurgy (PM) has been successfully used to produce titanium implants with controlled porosity without undesirable reactions or contaminations, proving to be an advantageous technique to process Ti parts [9]. These implants may have their bioactivity improved by various surface modification techniques, such as mechanical, physical and chemical methods. These methods can modify the metal surface properties on a range of scales [10]. However, it is recognized that material-host tissue interactions are principally governed by nanometric surface cues [7].

Mechanical methods (for example: grinding, polishing, blasting and machining) are subtractive processes that generate rough or smooth surfaces at the microscale, leading to improvement in cell adhesion. Physical methods (such as: thermal spray, ion implantation and deposition, physical vapor pressure deposition and glow discharge plasma) are surface modification techniques at micro and nanoscale that induce en- 
hancement of features like corrosion resistance, biocompatibility and wear resistance. Finally, the chemical methods (as acid treatment, alkali treatment, hydrogen peroxide treatment, sol-gel treatment, anodic oxidation and chemical vapor deposition method) also promote surface modification at micro and nanoscale, enabling the creation of micro or nanotopographies with enhanced features like biocompatibility, bioactivity, bone conduction and corrosion resistance. Moreover, they favor the removal of surface contamination [7, 10].

Regarding to mechanical and physical methods, the literature does not report studies on the application of these techniques for modifying the surface of porous Ti-based materials, suggesting that such approaches are not suitable for porous media or assuming that the findings would be the same reported for dense materials. For chemical methods, few works have reported the use of such techniques to modify the surface of porous Ti-based parts [11, 12]. However, recently, the use of controlled chemical oxidation to create reproducible nanopatterns on commercially pure dense $\mathrm{Ti}$ (cp Ti) or Ti alloy surfaces has been studied. By immersing the dense Ti-based material in an etching solution composed of concentrated sulfuric acid and aqueous hydrogen peroxide, it is possible to create a nanotexture on the surface that improves the biocompatibility and cell adhesion characteristics [1, 7, 13-15].

Based on literature review, it was noted that there are few reports about the use of the controlled chemical oxidation to modify the surface of porous Ti parts. In this context, the present work aimed to investigate and compare the nanotexture formation on commercially dense pure titanium sheets and porous titanium samples processed by powder metallurgy, in order to evaluate the chemical treatment outcome on porous media.

\section{MATERIALS AND METHODS}

Dense and porous titanium substrates were processed by methodology described in previous work [11].

\subsection{Dense titanium substrates}

Commercially pure titanium dense sheets - DTi (ASTM F67-00 grade 2) from Ti Brasil Ltda., with $20.62 \pm$ $8.33 \mu \mathrm{m}$ average grain size, were subjected to an acid descaling process to remove the contaminated layer formed during the rolling process, according to ASTM B600-91 standard, generating a surface of $3.81 \mu \mathrm{m}$ average roughness [11].

\subsection{Porous titanium substrates}

The PTi substrate was processed by powder metallurgy using Ti powder (ASTM F67-00 grade 2) manufactured by $\mathrm{HDH}$-hydrogenation-dehydrogenation process (Micron Metals/USA) and resulted in a sample with $61.38 \%$ average porosity and $85.29 \mu \mathrm{m}$ average roughness. Titanium powders with $125-149 \mu \mathrm{m}$ particle size range and ammonium bicarbonate, used as pore former additive, with $355-425 \mu \mathrm{m}$ particle size range, were manually mixed and isostatically pressed at $350 \mathrm{MPa}$. The pore former additive elimination was conducted at $170^{\circ} \mathrm{C}$ for 2 hours in a chamber furnace in air. Sintering was performed in a vacuum furnace (better than $10^{-5}$ Torr) at $1200^{\circ} \mathrm{C}$ for 2 hours [11]. After sintering, all samples were cleaned in an ultrasonic bath with neutral soap, acetone, ethyl alcohol and water.

\subsection{Controlled chemical oxidation treatment}

The cleaned DTi and PTi substrates were submitted to controlled chemical oxidation treatment with a mixture consisting of equal volumes of concentrated $\mathrm{H}_{2} \mathrm{SO}_{4}$ (95-97\%, reagent grade) and $30 \%$ aqueous $\mathrm{H}_{2} \mathrm{O}_{2}$ for 2 hours (DTi-2 and PTi-2) or 4 hours (DTi-4 and PTi-4) at room temperature under continuous agitation. The selection of immersion times was based on literature data [16]. Later, the samples were rinsed with deionized water in an ultrasonic bath for 10 minutes and air-dried in an oven for 1 hour at $60^{\circ} \mathrm{C}$. Before immersion of samples in the oxidative mixture, the components of the acid solution were mixed in an ice bath, since this combination releases a lot of heat. Then, the cooling bath was removed to allow the temperature to rise to room temperature.

\subsection{Characterization of samples}

The untreated (DTi-Control and PTi-Control) and treated (DTi-2, DTi-4, PTi-2 and PTi-4) samples were physical-chemically characterized by different techniques, as described below. 


\subsubsection{Field Emission Scanning Electron Microscopy (FEG-SEM)}

Surface topography characterization of untreated and treated samples was performed by Field Emission Scanning Electron Microscopy (FEG-SEM) and Energy Dispersive Spectroscopy (EDS) conducted in a FEI (model Quanta FEG 450) microscope, operated at $20 \mathrm{kV}$. The nanotexture size was measured by the calibrated scale bar from the FEG-SEM image software, using images with magnification of 300,000 times.

\subsubsection{Confocal Scanning Optical Microscopy (CSOM)}

Surface roughness from DTi-Control, DTi-2, DTi-4, PTi-Control, PTi-2 and PTi-4 samples was evaluated by Confocal Scanning Optical Microscopy (CSOM), using Axio CSM 700 confocal light microscope from Carl Zeiss. The roughness profile parameters were assessed in three different regions of the same image for each sample, in order to determine the average roughness ( $\mathrm{Ra})$, mean peak-to-valley height (Rz), and root-meansquare roughness $(\mathrm{Rq})$.

\subsubsection{X-ray Diffraction (XRD)}

Crystalline phases from DTi-Control, DTi-2, DTi-4, PTi-Control, PTi-2 and PTi-4 surfaces were determined by X-ray diffraction (XRD), using a X'Pert Pro diffractometer (Phillips, Panalytical) with CuK $\alpha$ radiation $(\lambda=0.154 \mathrm{~nm})$. The diffractometer was set at $40 \mathrm{kV}$ and $40 \mathrm{~mA}$. The data were collected in the $2 \theta$ interval from $30^{\circ}$ to $90^{\circ}$ with step size of $0.05^{\circ}$. Phase identification was performed for all samples using X'Pert Highscore Plus (Panalytical, version 3.0.0) software and Rietveld refinement was conducted for PTi-2 and PTi-4 samples by TOPAS 4.2 (Bruker) software.

\subsubsection{X-ray Photoelectron Spectroscopy (XPS)}

The electronic environment of DTi and PTi surfaces, before and after controlled chemical oxidation, was analyzed by X-ray Photoelectron Spectroscopy (XPS) technique using a Hemispherical Energy Analyzer (Specs Phoibos 150), equipped with an AlK $\alpha$ (1486.6 eV) non monochromatic source. The base pressure was less than $10^{-10}$ mbar. Survey spectra were recorded with $1.0 \mathrm{eV}$ step and $50 \mathrm{eV}$ analyzer pass energy and the high resolution regions with $0.08 \mathrm{eV}$ step and $20 \mathrm{eV}$ pass energy. The $\mathrm{C}_{1 \mathrm{~s}}$ peak at $284.6 \mathrm{eV}$ was used for spectra calibration. Spectra were Shirley background-subtracted across the energy region and fitted using CasaXPS Version 2.3.16 (Casa Software Ltd., Cheshire, UK).

Asymmetric line shapes were used for metallic components during spectra decomposition. According to the literature [17], asymmetry was used here as LA $(\alpha, \beta, \mathrm{m})$, where $\alpha$ and $\beta$ define the spread of the tail on either side of the Lorentzian component. The parameter $m$ specifies the width of the Gaussian line.

\section{RESULTS AND DISCUSSION}

As illustration, Figure 1 shows the DTi substate after acid descaling process. In Figure 1(a), it is observed a stereo microscope image (Olympus SZX 16 Stereo Microscope) and a scanning electron microscopy image (FEI ESEM Quanta 450 FEG microscope) is exhibited in Figure 1(b).
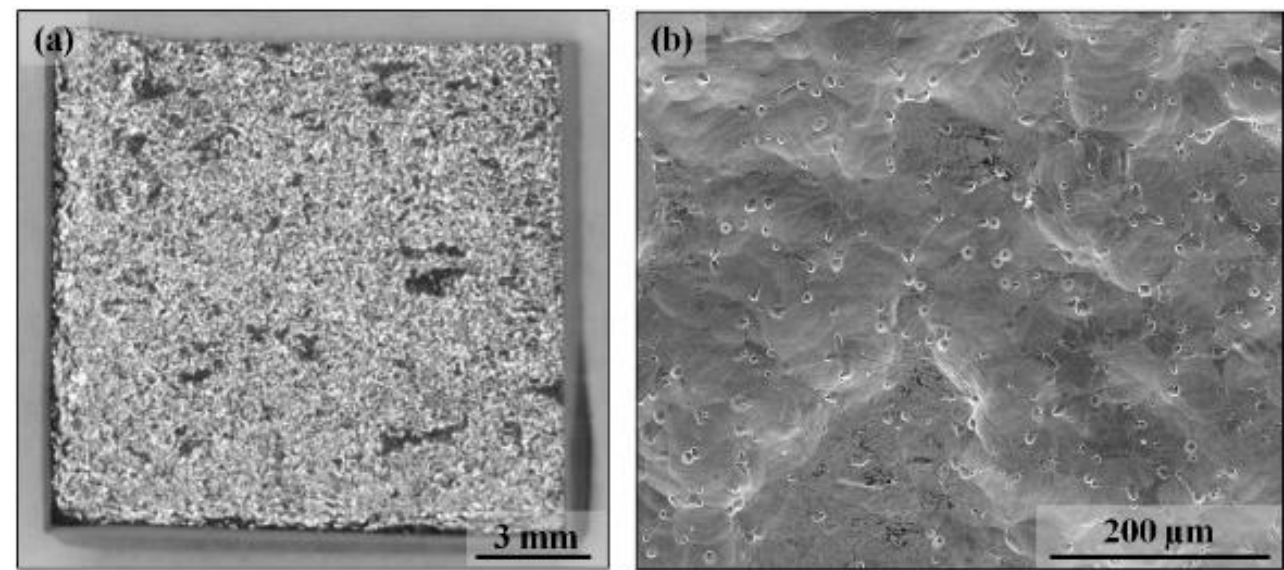

Figure 1: (a) Stereo microscope image and (b) SEM image of the DTi substrate after acid descaling process. 
Figure 2 presents microscope images of the porous titanium samples. Figure 2(a) displays a stereo microscope image (Olympus SZX 16 Stereo Microscope), while Figure 2(b) shows a scanning electron microscopy image (FEI ESEM Quanta 450 FEG microscope) of the porous pure Ti substrate - PTi.
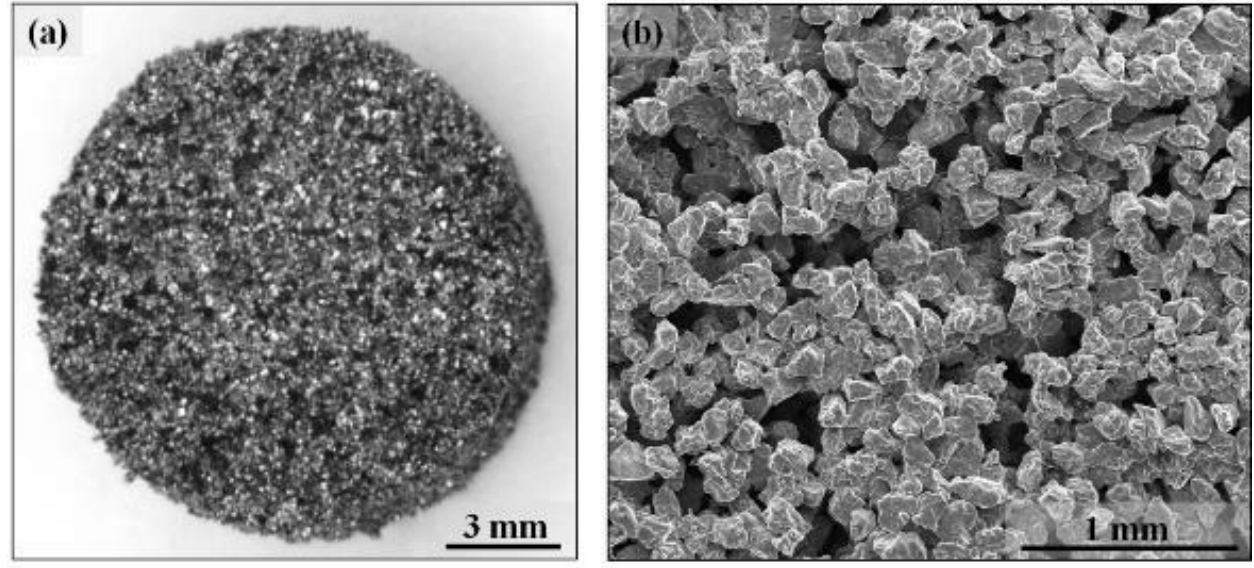

Figure 2: (a) Stereo microscope image and (b) SEM image of the PTi substrate processed by powder metallurgy.

\subsection{Field Emission Scanning Electron Microscopy (FEG-SEM)}

FEG-SEM images of untreated and treated samples are shown in Figure 3. Figures 3(a) and 3(d) exhibit the smooth surfaces of DTi-Control and PTi-Control samples, respectively. Figures 3(b), 3(c), 3(e) and 3(f) indicate that the combination of a concentrated acid and an oxidant agent was able to modify the dense and porous titanium surfaces, leading to a homogeneous nanotexture formation on the dense surfaces, Figures 3(b) and 3(c), and pore walls, Figures 3(e) and 3(f). Similar mechanism has been described in literature for commercially pure titanium dense surface $[16,18]$. However, it is important to highlight that studies on surface modification of porous titanium parts by controlled chemical oxidation with $\mathrm{H}_{2} \mathrm{SO}_{4}$ and $\mathrm{H}_{2} \mathrm{O}_{2}$ have not been substantially reported yet [15].

Table 1 displays the average diameters of nanotextures for each treated sample. No significant change in average diameters was noted by increasing the treatment time for both $\mathrm{Ti}$ surfaces, demonstrating that the immersion time of 2 hours was enough to promote topographic alteration.

Some authors have reported that topographical features at the nanoscale improve protein adsorption and cell adhesion, since this structure type changes surface area/energy and affects the protein orientation and denaturation, which plays a fundamental role in determining the outcome of the subsequent cell colonization $[7,13,15]$. 


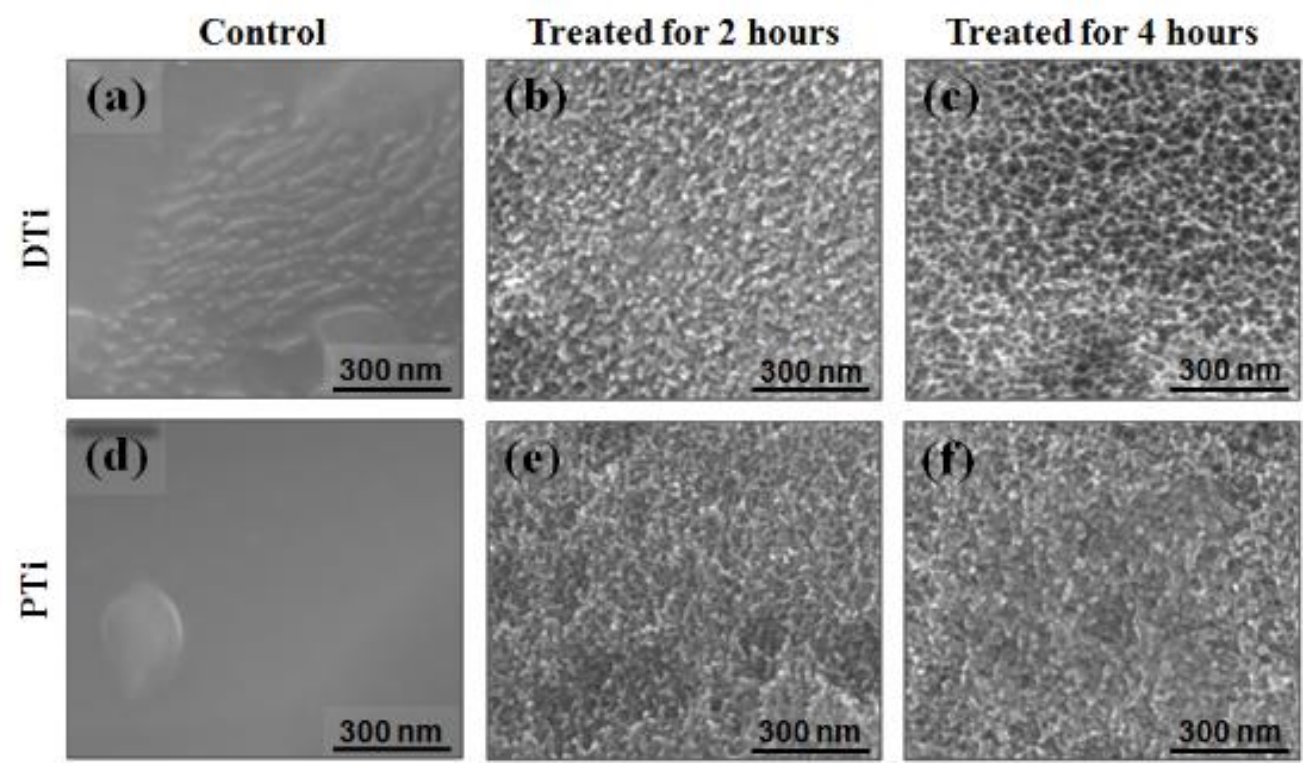

Figure 3: FEG-SEM images of samples: (a) DTi-Control; (b) DTi-2; (c) DTi-4; (d) PTi-Control; (e) PTi-2; (f) PTi-4.

Table 1: Average diameters of nanotextures for treated samples obtained by FEG-SEM image analyses.

\begin{tabular}{l|c|c|c|c}
\hline SAMPLE & DTi-2 & DTi-4 & PTi-2 & PTi-4 \\
\hline Average diameter $(\mathrm{nm})$ & $18.8 \pm 6.8$ & $18.1 \pm 4.4$ & $16.0 \pm 7.0$ & $16.1 \pm 5.4$ \\
\hline
\end{tabular}

The EDS spectra revealed mainly $\mathrm{Ti}$ and $\mathrm{O}$ peaks for all samples, suggesting no relevant chemical modification on the treated surfaces at micrometric scale, as shown in Figure 4. However, small peaks related to $\mathrm{Si}$ and $\mathrm{Cl}$ contaminants were detected. The presence of $\mathrm{Si}$ may be because the samples were stored in a desiccator with air circulation system, while the contamination source of $\mathrm{Cl}$ is unknown.
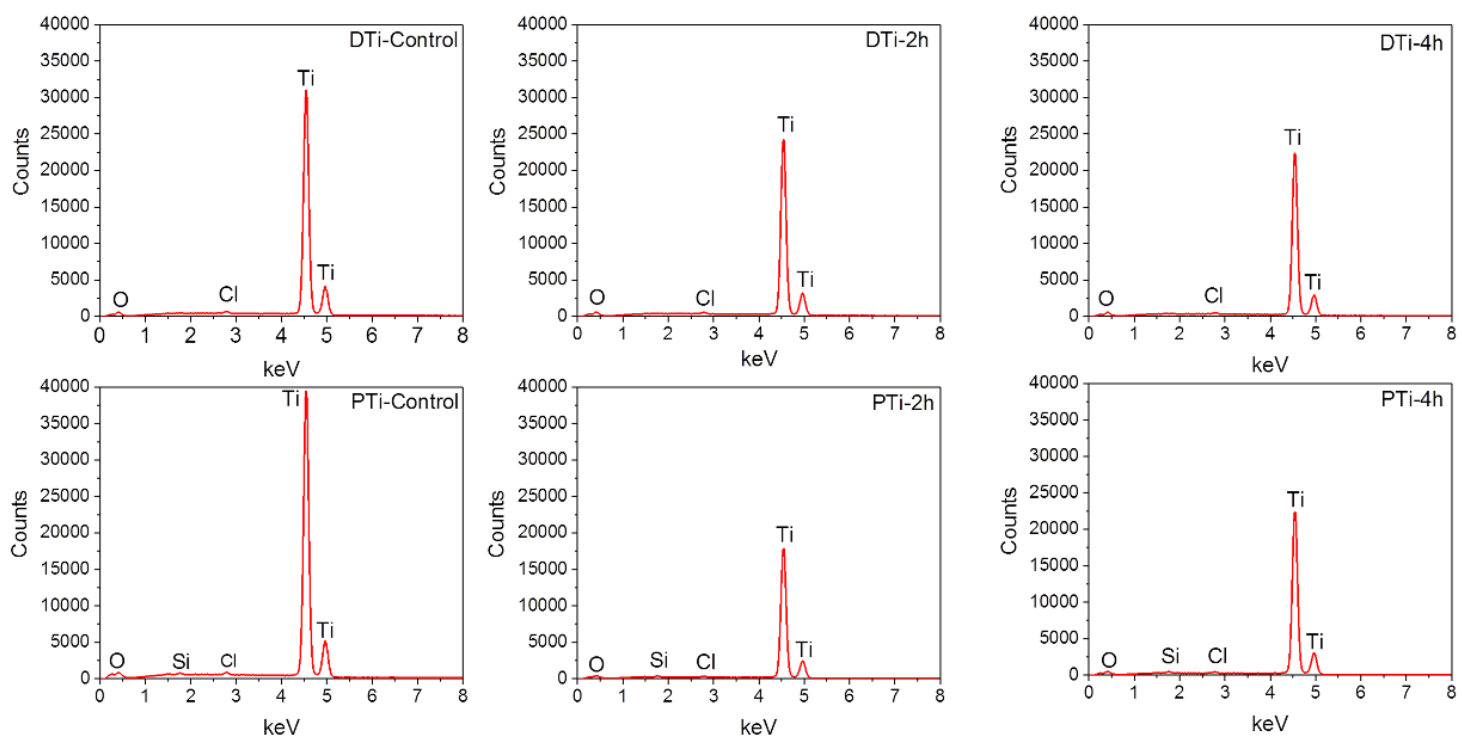

Figure 4: EDS spectra of DTi-Control, DTi-2, DTi-4, PTi-Control, PTi-2, PTi-4 samples.

\subsection{Confocal Scanning Optical Microscopy (CSOM)}

Table 2 presents the average roughness ( $\mathrm{Ra})$, the mean peak-to-valley height (Rz), and the root-mean-square roughness $(\mathrm{Rq})$ for untreated and treated Ti samples obtained by CSOM analyses. For DTi-Control, DTi-2 
and DTi-4 samples, results indicate that the controlled chemical oxidation treatment did not cause significant alterations in the $\mathrm{Ra}$ and $\mathrm{Rq}$ parameters at micrometric scale. However, Rz values showed a slight smoothing trend of treated dense surfaces. Moreover, the low standard deviations for these samples denote a uniform surface. The higher values of Ra, Rz, Rq, and standard deviations obtained for PTi-Control, PTi-2 and PTi-4 samples are due to the high porosity of surfaces. But these parameters also suggested a slight smoothing tendency of such treated surfaces. It is important to point out that roughness parameters are considerable references for further reproduction of samples [11]. The fact that no relevant micro-roughness modification was detected is not discouraging at all, because its effectiveness at nanoscale was demonstrated in Figures 3(b), 3(c), 3(e), 3(f).

The micro-roughness features presented by the dense samples are suitable for implant applications, since roughness on microscale $(0.2-2 \mu \mathrm{m} \mathrm{Ra})$ are widely used and clinically proven to improve osseointegration [15]. In addition, the macro-topographic profile with high rough surfaces of the porous samples $(>10$ $\mu \mathrm{m} \mathrm{Ra})$ is directly related their macro-porous structure, which is able to help in initial implant stability and provide volumetric spaces for growth of bone [19].

Table 2: Average roughness $(\mathrm{Ra})$, mean peak-to-valley height $(\mathrm{Rz})$, and root-mean-square roughness $(\mathrm{Rq})$ for control and treated Ti samples obtained by CSOM analyses.

\begin{tabular}{c|c|c|c|c|c|c}
\hline SAMPLE & DTI-CONTROL & DTI-2 & DTI-4 & PTI-CONTROL & PTI-2 & PTI-4 \\
\hline $\mathrm{Ra}(\mu \mathrm{m})$ & $1.1 \pm 0.1$ & $0.9 \pm 0.1$ & $1.1 \pm 0.1$ & $105.6 \pm 8.4$ & $94.6 \pm 1.0$ & $100.5 \pm 3.4$ \\
\hline $\mathrm{Rz}(\mu \mathrm{m})$ & $8.2 \pm 0.9$ & $6.2 \pm 0.4$ & $6.6 \pm 0.2$ & $591.8 \pm 42.4$ & $540.3 \pm 21.1$ & $566.6 \pm 51.9$ \\
\hline $\mathrm{Rq}(\mu \mathrm{m})$ & $1.4 \pm 0.1$ & $1.1 \pm 0.1$ & $1.3 \pm 0.1$ & $128.4 \pm 7.2$ & $115.6 \pm 1.9$ & $124.5 \pm 1.9$ \\
\hline
\end{tabular}

\subsection{X-ray Diffraction (XRD)}

XRD results of dense and porous samples are shown in Figure 5. From Figure 5(a), it is noted that the diffractograms only indicated the presence of metallic titanium (ICSD 076144) for DTi-Control, DTi-2 and DTi-4 samples. However, in Figure 5(b), the diffractograms of porous samples exhibited significant changes after chemical treatment, such as: i) PTi-Control sample presented only metallic titanium (ICSD 076144) crystalline phase as expected; ii) PTi-2 diffractogram indicated the presence of metallic titanium (ICSD 076144) and $\mathrm{Ti}_{2} \mathrm{O}$ (ICSD 023574); ii) PTi-4 diffractrogram showed the presence of metallic titanium (ICSD 076144) and $\mathrm{TiO}$ (ICSD 076266). $\mathrm{Ti}_{2} \mathrm{O}$ presents a hexagonal crystal system with space group $\mathrm{P}-3 \mathrm{~m} 1$ and lattice parameters: $\mathrm{a}=\mathrm{b}=2.96 \AA$ and $\mathrm{c}=4.83 \AA$. TiO oxide has a cubic crystal system with space group Fm$3 \mathrm{~m}$ and lattice parameters: $\mathrm{a}=\mathrm{b}=\mathrm{c}=4.172 \AA$. The chemical treatment time influenced the types of titanium oxides formed on porous metallic substrates and suggests that $\mathrm{Ti}_{2} \mathrm{O}$ gradually transforms into $\mathrm{TiO}$ when the oxidation time increases.

Therefore, these outcomes suggest that the controlled chemical oxidation treatment was more expressive on the porous samples than on the dense samples, since the titanium oxide phases were detected by XRD only on the treated porous substrates. This is probably related to the fact that the surface roughness is higher on PTi samples, as displayed in Table 2, which makes the porous surface more reactive due to the higher surface area [20], allowing to modify it in more extent. The presence of this oxide layer generated on the surface of porous samples certainly contributes to a better biocompatibility.

The Rietveld refinements resulted in $\mathrm{GOF}=1.04$ for PTi-2 sample and GOF=0.99 for PTi-4 sample, which suggested adequate adjustments. Phase quantification presented in Table 3 shows that the titanium oxide percentages increased with treatment time, while the metallic Ti species reduced, demonstrating a satisfactory performance of the $\mathrm{H}_{2} \mathrm{SO}_{4} / \mathrm{H}_{2} \mathrm{O}_{2}$ solution for modifying titanium porous surfaces. 

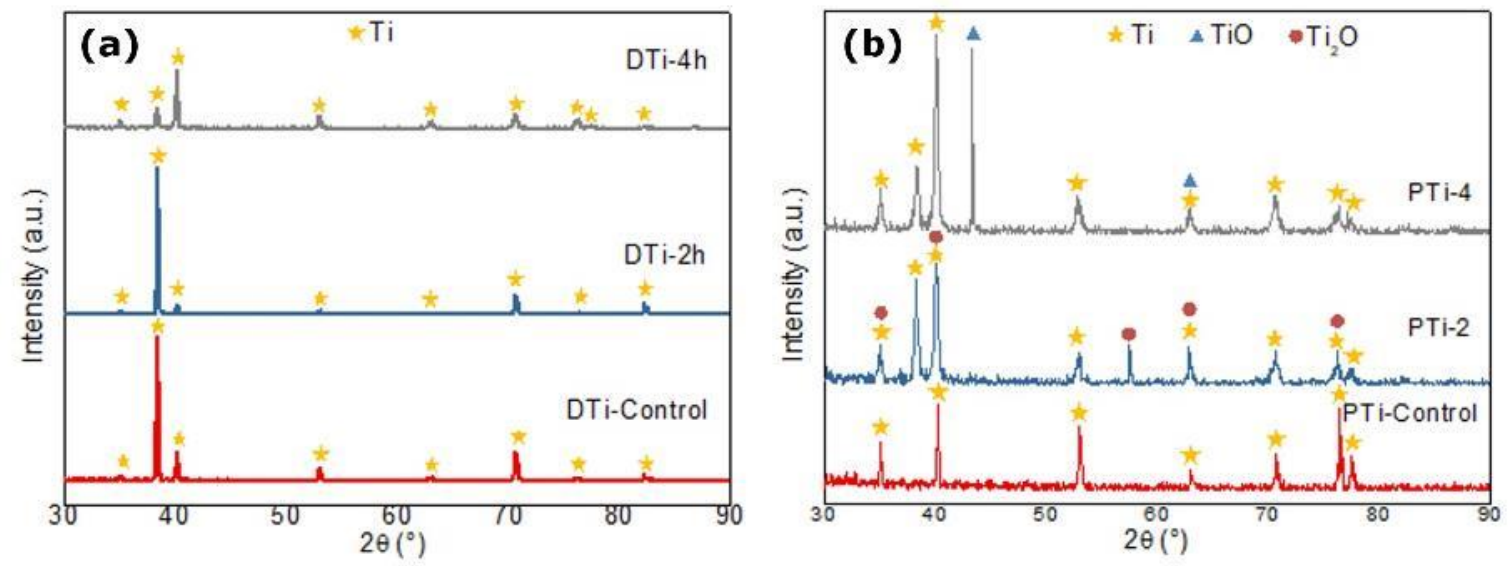

Figure 5: XRD results of dense samples (a) and porous samples (b).

Table 3: Rietveld refinement results for PTi-2 and PTi-4 samples.

\begin{tabular}{c|c|c|c}
\hline \multicolumn{4}{c}{ CRYSTALLINE PHASES } \\
\hline SAMPLE & $\mathrm{Ti}^{\text {METALLIC }}$ & $\mathrm{Ti}_{2} \mathrm{O}$ & $\mathrm{TiO}$ \\
\hline PTi-2 & $97.3 \%$ & $2.7 \%$ & - \\
\hline PTi-4 & $88.3 \%$ & - & $11.7 \%$ \\
\hline
\end{tabular}

\subsection{X-ray Photoelectron Spectroscopy (XPS)}

Core level spectra of $\mathrm{Ti}_{2 \mathrm{p}}$ and $\mathrm{O}_{1 \mathrm{~s}}$ are presented in Figures 6 and 7 for dense (DTi) and porous (PTi) titanium samples, respectively. DTi-Control (Figure 6a) and PTi-Control (Figure 7a) spectra were decomposed and well fitted into three components: $\mathrm{Ti}^{4+}, \mathrm{Ti}^{3+}, \mathrm{Ti}^{\text {metallic }}$. For both samples, the $\mathrm{Ti}_{2 \mathrm{p} 3 / 2}$ photoelectron peak occurred at $458.0 \mathrm{eV}$, with doublet separation of $5.7 \mathrm{eV}$. This component was attributed to $\mathrm{Ti}^{4+}$, suggesting that $\mathrm{TiO}_{2}$ is the major constituent of the oxide layer on surfaces [21, 22]. Moreover, the coexistence of lower valence oxide state assigned to $\mathrm{Ti}^{3+}$ like in $\mathrm{Ti}_{2} \mathrm{O}_{3}$ was found at $457.1 \mathrm{eV}$ (Figure 6a) and $457.5 \mathrm{eV}$ (Figure 7a) [23]. Well worth to mention the presence of $\mathrm{Ti}^{\text {metallic }}$ at $452.8 \mathrm{eV}$ for DTi-Control (Figure 6a) and $453.1 \mathrm{eV}$ for PTi-Control (Figure 7a) with doublet separation of $6.1 \mathrm{eV}$. Ti ${ }^{\text {metallic }}$ peak was considered to be from the $\mathrm{Ti}$ substrates, since the native oxide layer is very thin [24, 25].

In Figures 6(b), 6(c), 7(b) and 7(c), for DTi-2, DTi-4, PTi-2 and PTi-4 samples, respectively, $\mathrm{Ti}^{\text {metallic }}$ peak showed an intensity decrease, denoting a significant modification of the titanium surfaces by the controlled chemical oxidation treatment, suggesting a thickness increase of the $\mathrm{TiO}_{2}$ layer. The thickness increase of titanium oxide layer enhances the biocompatibility and kinetics of the bone formation process, since it avoids or reduces the diffusion of Ti ions from the bulk metal [25, 26]. Further, these results revealed that 2 hours of treatment were sufficient to modify the oxide layer, corroborating with SEM results (Figure 3).

Table 4 displays the titanium composition (atomic percentage -\%At) from the survey wide scan spectra and fractions (\% area) of $\mathrm{Ti}^{4+}, \mathrm{Ti}^{\text {metallic }}$ and $\mathrm{Ti}^{3+}$ from the $\mathrm{Ti}_{2 \mathrm{p}}$ core level spectra (Figures $6 \mathrm{a}, 6 \mathrm{~b}, 6 \mathrm{c}, 7 \mathrm{a}, 7 \mathrm{~b}, 7 \mathrm{c}$ ) for untreated and treated titanium surfaces. As expected, the survey spectra revealed the presence of carbon (C), oxygen $(\mathrm{O})$ and titanium (Ti). For both substrates, DTi and PTi, the controlled chemical oxidation treatment for 4 hours exposed more Ti on surface. However, DTi samples exhibited more Ti on surface than PTi samples, independently of the chemical treatment. A comparison between DTi-Control and DTi-4 surfaces suggests that the last sample slightly exposed more Ti on surface $(8.6 \% \mathrm{At})$. On the other hand, for PTiControl and PTi-4 surfaces, the Ti amount was significantly superior for the PTi-4 sample. In addition, no traces of $\mathrm{S}$ were found after chemical treatment, even though the samples were immersed in $\mathrm{H}_{2} \mathrm{SO}_{4} / \mathrm{H}_{2} \mathrm{O}_{2}$ solution.

From the $\mathrm{Ti}_{2 \mathrm{p}}$ core level spectra, the data in Table 4 indicates that the amount of $\mathrm{Ti}^{4+}$ was higher for PTi samples than DTi samples at any condition. It is also noted that the chemical treatment caused a reduction in the amount of $\mathrm{Ti}^{3+}$ with a subsequent increase in the amount of $\mathrm{Ti}^{4+}$, demonstrating a successful oxidation of both DTi and PTi surfaces. Further, the amount of $\mathrm{Ti}^{\text {metallic }}$ in DTi-Control sample was much higher than in 
PTi-Control sample. This phenomenon is probably related to the sintering process since any residual oxygen present in the furnace chamber can induce thermal oxidation of the titanium surface.

In Figures 6(d), 6(e), 6(f), 7(d), 7(e) and 7(f), the $\mathrm{O}_{1 \mathrm{~s}}$ core level XPS spectra were deconvoluted into three peaks: Ti-O bonds at $529.5 \mathrm{eV}, \mathrm{OH}^{-}$groups at $530.5 \mathrm{eV}$, and adsorbed $\mathrm{H}_{2} \mathrm{O}$ at $532.3 \mathrm{eV}$ [25]. Table 5 shows the fractions (\% area) of Ti-O bonds, $\mathrm{OH}^{-}$groups and adsorbed $\mathrm{H}_{2} \mathrm{O}$ on the untreated and treated titanium surfaces. It can be noticed that the amount of adsorbed $\mathrm{H}_{2} \mathrm{O}$ on surfaces decreased with the chemical treatment time, whereas the amount of $\mathrm{OH}^{-}$groups increased for both DTi and PTi substrates. Such behavior is expected for $\mathrm{H}_{2} \mathrm{O}_{2}$ treated $\mathrm{Ti}$ surfaces, and the increase of $\mathrm{OH}^{-}$groups has been correlated with an improvement of apatite nucleation and protein adsorption [17, 25, 26]. Therefore, the treated samples present improved biocompatibility due to the presence of more $\mathrm{OH}^{-}$groups on the surface.

It is important to mention that the identified titanium oxide species obtained by XRD, Figure 5(b), and by XPS, Figure 6(a) and Figure 7(a), were different. Such difference occurs because the two methods are used for completely different purposes. In theory, XRD examines the crystallinity of a sample within about $10 \mu \mathrm{m}$ of the surface, and XPS examines the elemental composition of a sample for depth profiling of surface layers from 2 to $8 \mathrm{~nm}$. XPS identifies which elements are present in the sample, in which concentrations, and in which oxidation states. Thus, the combined use of XPS and XRD is extremely beneficial in the identification of near-surface species, because XPS provides information from the surface to subsurface, while XRD profiles from the subsurface to the bulk [27].
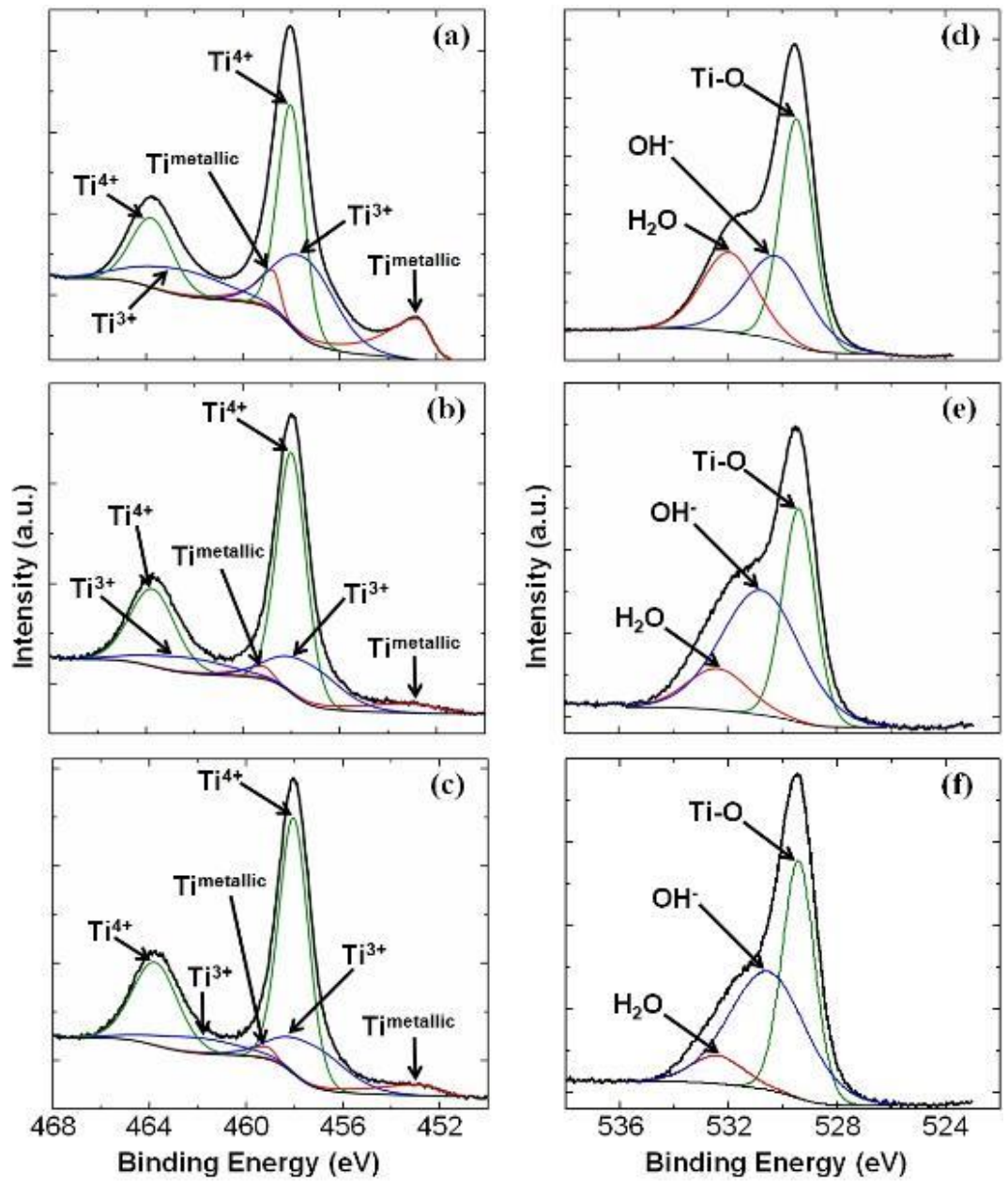

Figure 6: XPS spectra of the $\mathrm{Ti}_{2 p}$ and $\mathrm{O}_{1 \mathrm{~s}}$ core levels for commercially dense pure titanium samples: (a, d) DTi-Control; (b, e) DTi-2; (c, f) DTi-4. 

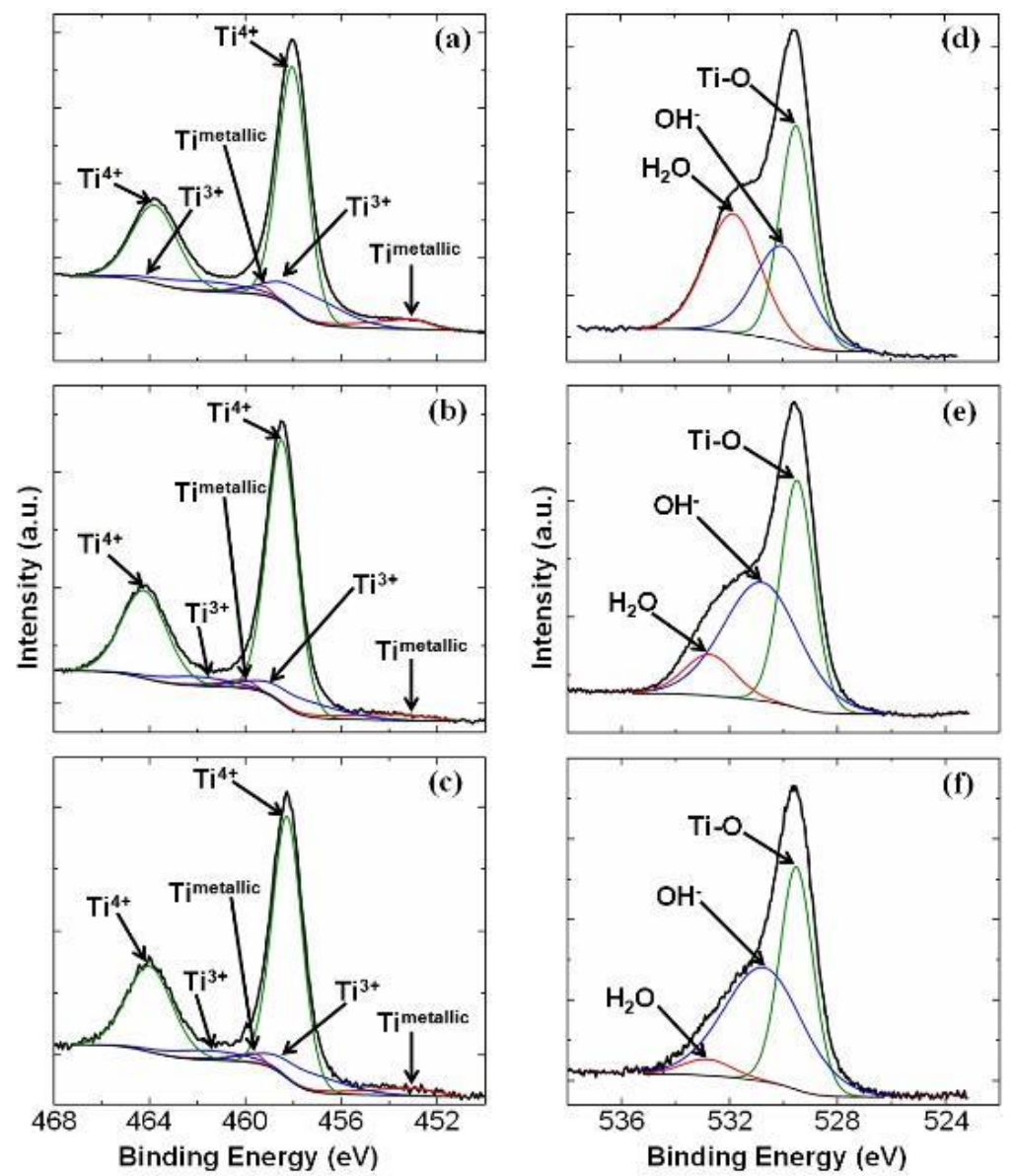

Figure 7: XPS spectra of the $\mathrm{Ti}_{2 \mathrm{p}}$ and $\mathrm{O}_{1 \mathrm{~s}}$ core levels for porous titanium samples: (a, d) PTi-Control; (b, e) PTi-2; (c, f) PTi-4.

Table 4: Titanium composition (atomic percentage -\%At) from the XPS survey wide scan spectra and fractions (\% area) of $\mathrm{Ti}^{4+}, \mathrm{Ti}^{\text {metallic }}$ and $\mathrm{Ti}^{3+}$ from the $\mathrm{Ti}_{2 \mathrm{p}}$ core level spectra of $\mathrm{Ti}$ samples.

\begin{tabular}{c|c|c|c|c}
\hline SAMPLE & $\mathrm{Ti}^{*}$ & $\mathrm{Ti}^{4+}$ & $\mathrm{Ti}^{3+}$ & Ti $^{\text {METALLIC+*}}$ \\
\hline DTi-Control & 8.2 & 44.4 & 37.3 & 18.3 \\
\hline DTi-2 & 8.0 & 66.4 & 24.7 & 8.9 \\
\hline DTi-4 & 8.6 & 67.6 & 24.8 & 7.6 \\
\hline PTi-Control & 6.4 & 73.4 & 19.1 & 7.5 \\
\hline PTi-2 & 6.8 & 80.1 & 13.0 & 6.9 \\
\hline PTi-4 & 7.9 & 78.6 & 14.6 & 6.8 \\
\hline
\end{tabular}

* From survey surface wide spectra scan. ** Asymmetric peak-shape LA $(1.1,5,7)[17]$. 
Table 5: Fractions (\% area) of Ti-O bonds, $\mathrm{OH}^{-}$groups and adsorbed $\mathrm{H}_{2} \mathrm{O}$ on the untreated and treated titanium surfaces obtained from the $\mathrm{O}_{1 \mathrm{~s}}$ core level XPS spectra.

\begin{tabular}{c|c|c|c}
\hline SAMPLE & Ti-O BONDS & OH GROUPS & ADSORBED $\mathbf{H}_{2} \mathbf{O}$ \\
\hline DTi-Control & 43.2 & 31.5 & 25.3 \\
\hline DTi-2 & 35.9 & 50.9 & 13.2 \\
\hline DTi-4 & 41.9 & 49.8 & 8.3 \\
\hline PTi-Control & 37.6 & 28.1 & 34.3 \\
\hline PTi-2 & 40.3 & 48.5 & 11.2 \\
\hline PTi-4 & 43.1 & 52.2 & 4.7 \\
\hline
\end{tabular}

\section{CONCLUSIONS}

A chemical patterning approach using a combination of concentrated acid and oxidant was able to generate a nanotexture on dense and porous titanium surfaces. The findings indicated that both times of controlled chemical oxidation treatment promoted similar modifications in surface properties, such as nanotexture and chemical composition, suggesting that 2 hours were enough to induce the surface alterations at the nanoscale. The treated samples presented an oxide layer consisting predominantly of titanium dioxide with negative charge provided by the presence of hydroxyl groups, which can offer special surface functionalities to titanium implants like improved biocompatibility. In addition, the chemical treatment occurred in more extent on the porous samples than on the dense samples, suggesting that the surface characteristics, for example, high roughness, is an important variable when it comes to metal surface modification. Therefore, it was proved that porous Ti parts did not respond in the exact same way as dense Ti parts to the chemical oxidation, because of the higher surface area intrinsic of porous media.

\section{ACKOWLEDGEMENTS}

The authors thank to Carlos Chagas Filho Research Foundation of the State of Rio de Janeiro (FAPERJ/Brazil), National Council for Scientific and Technological Development (CNPq/Brazil) and National System of Nanotechnology Laboratories (MCTI/SisNANO/INT-CENANO-CNPq Process number 442604/2019-0) for financial support, Brazilian Center for Research in Physics (CBPF/Brazil) for XRD analyses.

\section{BIBLIOGRAPHY}

[1] VETRONE, F., VARIOLA, F., OLIVEIRA, P.T., et al., "Nanoscale oxidative patterning of metallic surfaces to modulate cell activity and fate", Nano Letters, v. 9, n. 2, pp. 659-665, Jan. 2009.

[2] PUCKETT, S.D., LEE, P.P., CIOMBOR, D.M., et al., "Nanotextured titanium surfaces for enhancing skin growth on transcutaneous osseointegrated devices", Acta Biomaterialia, v. 6, n. 6, pp. 2352-2362, Jun. 2010 .

[3] LIU, W., LIU, S., WANG, L., "Surface modification of biomedical titanium alloy: micromorphology, microstructure evolution and biomedical applications", Coatings, v. 9, n. 4, pp. 249-271, April 2019.

[4] CHRCANOVIC, B.R., MARTINS, M.D., "Study of the influence of acid etching treatments on the superficial characteristics of Ti”, Materials Research, v. 17, n. 2, pp. 373-380, April 2014.

[5] CAPARRÓS, C., ORTIZ-HERNANDEZ, M., MOLMENEU, M., et al., "Bioactive macroporous titanium implants highly interconnected", Journal of Materials Science: Materials in Medicine, v. 27, pp. 151-161, Oct. 2016.

[6] NOURI, A. "Titanium foam scaffolds for dental applications", In: Wen, C. (ed), Metallic Foam Bone: Processing, Modification and Characterization and Properties, 1 ed., chapter 4, Amsterdam, Netherlands, Elsevier, 2017.

[7] VARIOLA, F., BRUNSKI, J.B., ORSINI, G., et al., "Nanoscale surface modifications of medically relevant metals: state-of-the art and perspectives", Nanoscale, v. 3, n. 2, pp. 335-353, Feb. 2011. 
[8] SALOU, L., HOORNAERT, A., LOUARN, G., et al., "Enhanced osseointegration of titanium implants with nanostructured surfaces: an experimental study in rabbits", Acta Biomaterialia, v. 11, pp. 494-502, Jan. 2015.

[9] LASCANO, S., ARÉVAlO, C., MONTEALEGRE-MELENDEZ, I., et al., "Porous titanium for biomedical applications: evaluation of the conventional powder metallurgy frontier and space-holder technique", Applied Science, v. 9, pp. 982-994, Mar. 2019.

[10] SHARAN, J., LALE, S.V., KOUL, V., et al., "An overview of surface modifications of titanium and its alloys for biomedical applications", Trends in Biomaterials and Artificial Organs, v. 29, n. 2, pp. 176-187, Dec. 2014.

[11] RIBEIRO, A.A., BALESTRA, R.M., ROCHA, M.N., et al., "Dense and porous titanium substrates with biomimetic calcium phosphate coating”, Applied Surface Science, v. 265, pp. 250-256, Jan. 2013.

[12] SILVA, R.S., RIBEIRO, A.A., "Characterization of Ti-35Nb alloy surface modified by controlled chemical oxidation for surgical implant applications", Revista Matéria, v. 24, n. 3, e-12396, Sep. 2019.

[13] OLIVEIRA, P.T., NANCI, A., "Nanotexturing of titanium-based surfaces upregulates expression of bone sialoprotein and osteopontin by cultured osteogenic cells", Biomaterials, v. 25, n. 3, pp. 403-413, Feb. 2004.

[14] FREITAS, G.P., LOPES, H.B., MARTINS-NETO, E.C., et al., "Effect of nanotopography created by $\mathrm{H}_{2} \mathrm{SO}_{4} / \mathrm{H}_{2} \mathrm{O}_{2}$ on bone response to titanium implant", Journal of Oral Implantology, v. 42, n. 3, pp. 240-247, Jun. 2016.

[15] BARTHESA, J., CAZZOLAB, M., MULLERA, C., et al., "Controlling porous titanium/soft tissue interactions with an innovative surface chemical treatment: Responses of macrophages and fibroblasts", Materials Science \& Engineering C, v. 112, 110845, Mar. 2020.

[16] YI, J.H., BERNARD, C., VARIOLA, F., et al., "Characterization of a bioactive nanotextured surface created by controlled chemical oxidation of titanium", Surface Science, v. 600, pp. 4613-4621, Oct. 2006.

[17] BIESINGER, M.C., LAU, L.W.M., GERSON, A.R., et al., "Resolving surface chemical states in XPS analysis of first row transition metals, oxides and hydroxides: Sc, Ti, V, Cu and Zn", Applied Surface Science, v. 257, n. 3, pp. 887-98, Nov. 2010.

[18] NAZAROV, D.V., ZEMTSOVA, E.G., SOLOKHIN, A.Y., et al., "Modification of the surface topography and composition of ultrafine and coarse grained titanium by chemical etching", Nanomaterials, v. 7, n. 1, pp. 1-15, Jan. 2017.

[19] ALLA, R.K., GINJUPALLI, K., UPADHYA, N., et al., "Surface roughness of implants: a review", Trends in Biomaterials and Artificial Organs, v. 25, n. 3, pp. 112-118, May 2011.

[20] DENG, H., MOLINS, S., TREBOTICH, D., et al., "Pore-scale numerical investigation of the impacts of surface roughness: upscaling of reaction rates in rough fractures", Geochimica et Cosmochimica Acta, v. 239, pp. 374-389, Oct. 2018.

[21] CASTILlO, R., KOCH, B., RUIZ, P., et al., "Influence of the amount of titania on the texture and structure of titania supported on silica”, Journal of Catalysis, v. 161, n. 2, pp. 524-529, Jul. 1996.

[22] SANJINÉS, R., TANG, H., BERGER, H., et al., "Electronic structure of anatase $\mathrm{TiO}_{2}$ oxide", Journal of Applied Physics, v. 75, n. 6, pp. 2945-2951, Mar. 1994.

[23] HELTH, A., GOSTIN, P.F., OSWALD, S., et al., "Chemical nanoroughening of Ti40Nb surfaces and its effect on human mesenchymal stromal cell response", Journal of Biomedical Materials Research - Part B: Applied Biomaterials, v. 102, n. 1, pp. 31-41, Jul. 2013.

[24] TAKEMOTO, S., YAMAMOTO, T., TSURU, K., et al., "Platelet adhesion on titanium oxide gels: effect of surface oxidation”, Biomaterials, v. 25, n. 17, pp. 3485-3492, Aug. 2004.

[25] WANG, G., LI, J., LV, K., et al., "Surface thermal oxidation on titanium implants to enhance osteogenic activity and in vivo osseointegration”, Scientific Reports, v. 6, 31769, pp. 1-13, Aug. 2016.

[26] WEXEL, C.L., THOMSEM, P., ARONSSON, B.O., et al., "Bone response to surface-modified titanium implants: studies on the early tissue response to implants with different surface characteristics", International Journal of Biomaterials, ID 412482, pp. 1-10, Sep. 2013.

[27] KERBER, S.J., BARR, T.L., MANN, G.P., et al., "The complementary nature of X-ray photoelectron spectroscopy and angle-resolved X-ray diffraction part I: background and theory”, Journal of Materials Engineering and Performance, v. 7, pp. 329-333, Jun. 1998. 


\section{ORCID}

Alexandre Antunes Ribeiro

https://orcid.org/0000-0002-5299-4241

Rodrigo Sacramento da Silva

https://orcid.org/0000-0002-6465-9248

Débora Vieira Way

https://orcid.org/0000-0003-1248-2361

Laís de Souza Alves

https://orcid.org/0000-0003-0541-1151

Erika Batista Silveira

https://orcid.org/0000-0002-2439-891X

Fabiana Magalhães Teixeira Mendes

https://orcid.org/0000-0002-2564-4334

Marize Varella de Oliveira

https://orcid.org/0000-0001-9341-7582 